\title{
Osteoblastoma of the Lateral Skull Base: Work-Up, Surgical Management, and a Review of the Literature
}

\author{
Craig Miller $^{1}$ Rihan Khan ${ }^{2}$ G. Michael Lemole, Jr. ${ }^{3} \quad$ Abraham Jacob $^{1}$
}

${ }^{1}$ Division of Otolaryngology, The University of Arizona Ear Institute, University of Arizona, Arizona, United States

2 Department of Radiology, The University of Arizona, Arizona, United States

${ }^{3}$ Division of Neurosurgery, The University of Arizona, Arizona, United States

Address for correspondence Abraham Jacob, MD, Arizona Cancer Center; 1515 N. Campbell Ave, Room 0973, Tucson, AZ 85719, United States

(e-mail: ajacob@surgery.arizona.edu).

J Neurol Surg Rep 2014;75:e189.

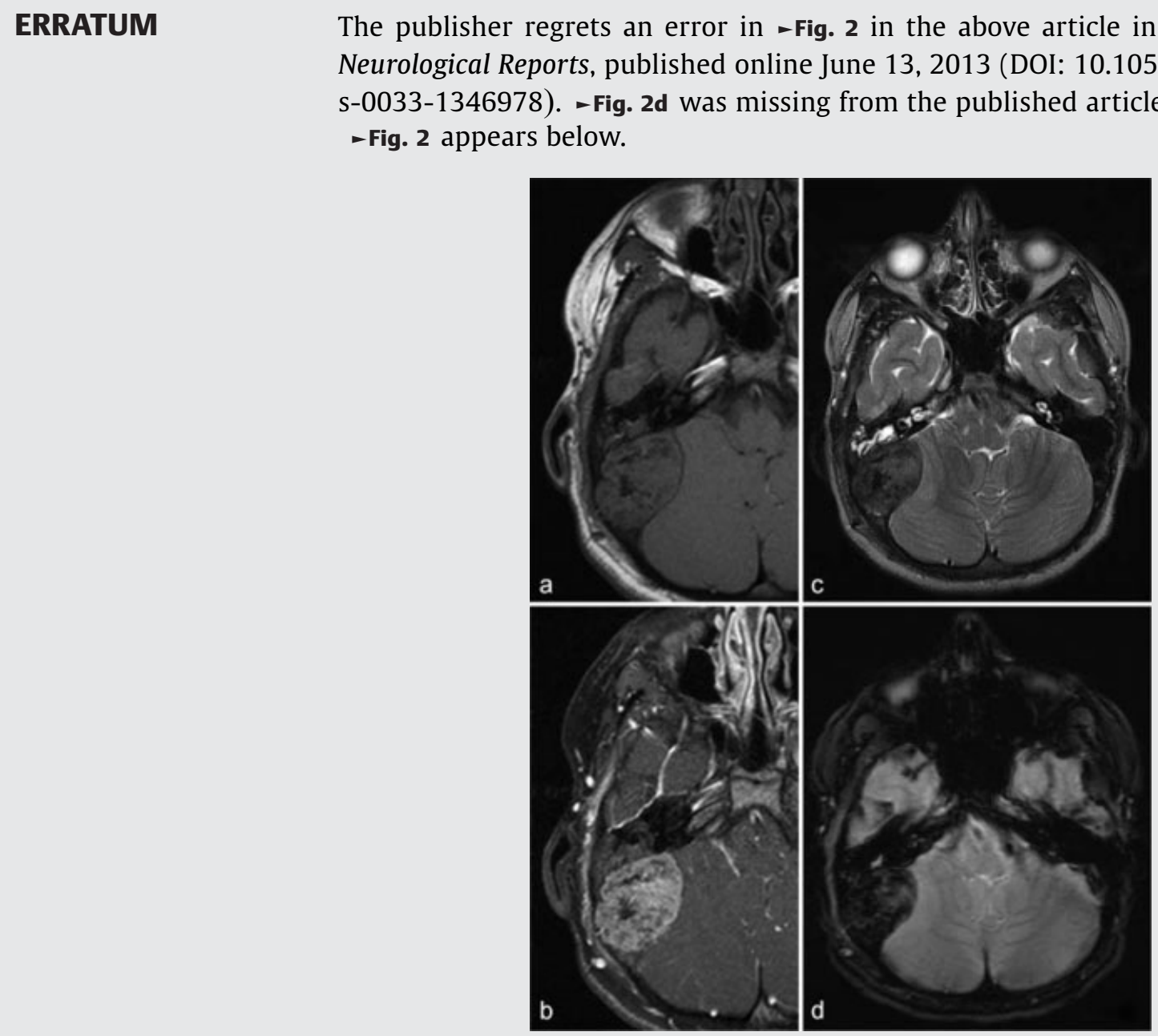

Fig. 2 (a) Axial T1 precontrast and (b) T1 postcontrast magnetic resonance imaging (MRI) images show a T1 dark mass lesion, which avidly enhances. (c) Axial T2 MRI shows that the lesion is significantly dark, indicating the relative lack of water content in the mass, whereas (d) axial gradient MRI shows extensive dark signal related to the calcification.

(c) 2014 Georg Thieme Verlag KG Stuttgart . New York
DOI http://dx.doi.org/ $10.1055 / \mathrm{s}-0033-1349675$. ISSN 2193-6358. 